\title{
A saúde da família sob as lentes da higiene mental
}

\author{
Family health through the \\ lens of mental hygiene
}

Renata Heller de Moura

Professora do Departamento de Psicologia da Universidade Estadual de Maringá/Paraná (UEM/PR) e pesquisadora do Grupo de Estudos e Pesquisas sobre o Higienismo e Eugenismo (GEPHE) da UEM/PR. rena_heller@hotmail.com

\section{Maria Lucia Boarini}

Professora do Departamento de Psicologia e do Programa de Pós-graduação em Psicologia da UEM/PR, pesquisadora e coordenadora do GEPHE da UEM/PR.

mlboarini@uol.com.br

Universidade Estadual de Maringá Av. Colombo, 5790 87302-220 - Maringá - PR - Brasil

Recebido para publicação em janeiro de 2011. Aprovado para publicação em dezembro de 2011.

MOURA, Renata Heller de; BOARINI, Maria Lucia. A saúde da família sob as lentes da higiene mental. História, Ciências, Saúde - Manguinhos, Rio de Janeiro, v.19, n.1, jan.-mar. 2012, p.217-235

Resumo

Procura instigar o debate sobre os determinantes sócio-históricos que condicionam a construção de políticas públicas de saúde mental aplicáveis ao contexto familiar brasileiro. As atuais políticas têm privilegiado a família como lugar estratégico de ações voltadas para a transformação social, com intervenção de vários atores, entre eles, psicólogos. Ao recuperar alguns pontos do ideário de higiene mental percebeu-se que esse discurso não é novidade na história da saúde brasileira. Embora os tempos, as famílias e os profissionais sejam outros, compreendeu-se que a busca de solução para a 'crise' da sociedade continua sendo atribuída ao indivíduo particular. A família, como expressão desse indivíduo, tem sido chamada para assumir responsabilidades que levem a sociedade na direção da 'ordem' e do 'progresso' da nação.

Palavras-chave: família; higiene mental; Programa Saúde da Família/Estratégia Saúde da Família; saúde pública; saúde mental.

\section{Abstract}

The article is meant to stimulate debate about the social and historical determinants that shape the construction of public mental health policy within the context of the Brazilian family. Current policies have emphasized the family as a strategic target of initiatives aimed at social transformation, with the intervention of different actors, including psychologists. An examination of some ideas from the field of mental hygiene suggests that this discourse is nothing new in the history of Brazilian health. While today's times, families, and professionals are different, the search for a solution to the so-called crisis of society still focuses on the individual. The family, as the expression of this individual, has been called upon to assume responsibilities that push society towards 'order' and 'progress' for the Nation.

Keywords: family; mental hygiene; Family Health Program/Family Health Strategy; public health; mental health. 
$\mathrm{C}$ ircunscrito na rede de relações sociais de produção da existência humana, o termo família é de difícil definição. "Podemos afirmar que não existe 'a família', mas sim várias combinações possíveis circunscritas histórica e socialmente" (Fukui, Bruschini, 1981, p.3). Tanto a tríade 'pai, mãe e filhos' pode ser tomada como um exemplo de configuração familiar quanto um grupo composto por uma vasta parentela. É possível observar que, de acordo com cada momento histórico, a família apresenta uma configuração social, política, econômica e cultural. "É um princípio ativo. Nunca permanece estacionária", como disse Lewis Morgan (1877, citado por Engels, 2006, p.41). Nessa perspectiva, toda forma de organização familiar é transitória e histórica, tornando-se expressão da sociedade da qual faz parte.

Atualmente, os estudos sobre família têm-se constituído em um vasto campo de pesquisa. No Brasil, um trabalho que nos ajuda a compreender o modo como, nas últimas décadas do século XX, a família tem sido abordada sob diferentes enfoques e definições e suscitado muitas discussões em torno de seu referencial teórico e métodos de análise é o de Teruya (2000). A autora procura evidenciar que debates polêmicos e diálogos ora amistosos, ora antagônicos têm proporcionado um crescimento de análises acerca do tema família, o que tem contribuído para superação de modelos analíticos simplistas.

No âmbito das políticas públicas, vários autores apontam que os programas de política social de nosso país têm entendido a família como base estratégica para a construção de suas ações e como detentora de um importante papel na transformação social (Carvalho, 1995; Mioto, 2004; Acosta, Vitale, 2005).

Especificamente na área da saúde pública brasileira, a construção de ações e serviços que se aproximem da dinâmica familiar encontrou forte expressão no Programa Saúde da Família (PSF), regulamentado pela Portaria no 692/GM/MS/94 (Brasil, 2001). O PSF foi criado no Brasil em 1994, como estratégia de reorganização do sistema de atenção à saúde e em resposta a uma série de reflexões acerca da necessidade de reorganização dos serviços de saúde no mundo, das quais relembramos a Declaração de Alma-Ata (Opas, 1978) e a Carta de Ottawa (Opas, 1986). Essas reflexões repercutiam no Brasil, ecoando na Oitava Conferência Nacional de Saúde (1986) e na Constituição Brasileira de 1988. A reorganização do modelo de atenção à saúde passou a preconizar o desenvolvimento de serviços de atenção primária à saúde da população, ou seja, de "cuidados essenciais de saúde baseados em métodos e tecnologias práticas, cientificamente bem fundamentadas e socialmente aceitáveis, colocadas ao alcance universal de indivíduos e famílias da comunidade, mediante sua plena participação e a um custo que a comunidade e o país possam manter em cada fase de seu desenvolvimento, no espírito de autoconfiança e automedicação" (Opas, 1978, p.1).

Por meio da Estratégia Saúde da Família, o Ministério da Saúde propõe o desenvolvimento de ações e serviços em integração com a comunidade, fazendo a busca ativa de casos, com intervenção oportuna e precoce, dando ênfase à prevenção e à educação em saúde. Uma estratégia que intervém por extensão de cobertura territorial e facilitação do acesso, continuidade das ações de saúde e trabalho em equipe multiprofissional. Essa equipe é composta minimamente por: enfermeiro, auxiliar ou técnico de enfermagem, médico, agente comunitário de saúde, cirurgião dentista, auxiliar de consultório dentário e técnico de higiene dental (Brasil, 2001). 
Mais recentemente, a equipe mínima de saúde da família passou a contar com o apoio de outros profissionais de nível técnico e nível superior. De acordo com a portaria no 157/GM/ MS/2008 (Brasil, 2008), entre os profissionais que compõem o Núcleo de Apoio à Saúde da Família, estão os psicólogos.

Tal fato vem estimulando discussões e pesquisas que tratam, em geral, da criação e desenvolvimento de possíveis práticas terapêuticas psicológicas que se apliquem ao contexto familiar atual. Pouca relevância se atribui à discussão acerca dos aspectos sócio-históricos que condicionam essa intervenção. Ou seja, o que, histórica e socialmente, tem determinado a família como base estratégica para a construção de políticas públicas do Brasil? Por que a família tem sido compreendida como detentora de um importante papel na transformação social? E por que até mesmo serviços de saúde mental precisam ser desenvolvidos junto à família brasileira?

Discutir os fenômenos sociais da atualidade é um trabalho difícil, pelo fato de que a sociedade é um contínuo 'vir a ser', escapando das lentes dos seus observadores pelo fato de esses mesmos serem também os personagens dos contextos observados. Outrossim, a existência de um discurso, na atualidade, sobre a necessidade de uma intervenção em saúde pública no contexto familiar que atue na área de saúde mental coloca em questão o significado dessa intervenção, e o recurso à história pode contribuir no seu desvelamento.

Na história, na qual os fatos estão evidenciados e elucidados pelo tempo, nossas lentes poderão focalizar fatos, acontecimentos e personagens que outrora já realizaram intervenções relacionadas à saúde da família brasileira. Podemos ampliar o nosso foco e observar a articulação dessa intervenção com os diversos setores sociais, para os quais essa intervenção interessou, e podemos ainda perceber a aproximação entre ciência e Estado, ocorrida no período. Veremos que foram desenvolvidas políticas de saúde pública que iam desde o aspecto físico da família brasileira da época, chegando até o aspecto mental. Tratase de um trabalho não menos difícil de empreender, mas acreditamos que ele permite maior visibilidade. "Assim, tentamos buscar origens e refazer a história, como num país de espelhos em que, ao se andar para trás se consegue chegar ao local desejado mais a frente" (Luz, 1982, p.104).

Voltando-nos para a história da saúde pública do Brasil, no que diz respeito ao aspecto da saúde mental, que é enfocado neste trabalho, veremos que, no início do século XX, uma elite intelectual composta de profissionais de diversas áreas, principalmente da área médica, com forte engajamento político-social, criou a Liga Brasileira de Higiene Mental (LBHM). O objetivo do presente estudo é o de investigar como o movimento de higiene mental procurou contribuir para a formação de uma concepção de família nuclear e conjugal 'mentalmente saudável' e 'moralmente higiênica', nas décadas de 1920 a 1940, no Brasil.

Em particular, interessamo-nos em compreender como os preceitos de higiene mental veiculados pela LBHM apresentaram propostas e preceitos para regular o convívio familiar, dando novas significações aos vínculos entre homens e mulheres, adultos e crianças, modelando-os ao estilo 'burguês'. Para tanto, dos documentos da época, elegemos como fonte primária os Arquivos Brasileiros de Higiene Mental, órgão oficial da LBHM.

Em nossa análise, consideramos que os movimentos científicos, sociais e políticos são construídos na rede de relações sociais que os homens estabelecem entre si, em sua forma 
de viver e reproduzir, expressando ideias e concepções determinadas historicamente. O período em foco neste estudo (1920-1940) foi marcado pelas duas grandes guerras mundiais e pelo capitalismo imperialista que, entre outros aspectos, contribuiu para o florescimento da industrialização brasileira e para o surgimento de um acalorado discurso nacionalista (Basbaum, 1976).

O homem ideal para construção desta nação deveria ser dotado de 'hábitos sadios' física e mentalmente, desenvolvidos desde a infância pelo contexto familiar. Os higienistas acreditavam que, com auxílio adequado, a 'família higiênica' estaria pronta para assumir seu papel social frente à nação em construção, neutralizando a reprodução de mazelas sociais e de 'más adaptações' individuais.

Pelo distanciamento temporal que nos separa desses eventos, o estudo desse movimento pode possibilitar a construção de reflexões acerca de seus desdobramentos nas propostas e encaminhamentos atualmente apontados pelos programas de saúde pública à família brasileira. Mas um esclarecimento se faz necessário. Não temos como objetivo aqui traçar um quadro comparativo entre períodos históricos tão distintos, equiparando a intervenção da LBHM sobre a higiene mental da família brasileira dos anos 1920-1940 com as atuais propostas de programas da saúde pública sobre a saúde mental da família brasileira contemporânea. Os tempos, as famílias e os profissionais são outros.

O que pretendemos com esse trabalho de resgate histórico acerca das intervenções da LBHM sobre a família brasileira é incrementar o debate sobre os determinantes sóciohistóricos que condicionam a construção de políticas públicas de saúde mental para o contexto familiar brasileiro. Esperamos que em nossa discussão fique claro que, embora os períodos e o contexto situacional de outrora e da atualidade sejam diferentes, o fato em comum entre eles é a matriz filosófico-ideológica que, predominantemente, orienta a sociedade nesses dois momentos históricos: a matriz positivista fundada na ideia de que a estabilização da crise social depende da estabilidade moral dos indivíduos e a ideia de que a busca da solução para a 'crise' da sociedade depende do indivíduo, que é chamado para assumir responsabilidades sociais na direção da 'ordem' e do 'progresso' da nação. Continuar convocando a família para assumir essas responsabilidades sociais é focalizar a árvore e perder de vista o bosque, como disse Engels (1877).

\section{Compreendendo os determinantes sócio-históricos}

Procurando compreender os determinantes sócio-históricos que condicionam a construção de intervenções em saúde mental sobre o contexto familiar brasileiro nos voltamos para a história da saúde pública e constatamos, como já afirmamos anteriormente, que importantes intelectuais, em sua maioria médicos, se dispuseram a refletir e a propor encaminhamentos para o desenvolvimento de uma ordem familiar brasileira desde o século XIX. Aqui nos referimos ao movimento higienista e, mais especificamente, ao seu desdobramento, denominado movimento de higiene mental. Esses movimentos tiveram expressão internacional e oficialmente deixaram suas marcas no Brasil no período aproximado das décadas de 1920 a 1940. 
Fruto de uma intensa participação político-social de profissionais de diversas áreas, principalmente da área médica, foi criada a já mencionada Liga Brasileira de Higiene Mental, sendo reconhecida como órgão de utilidade pública pelo decreto federal oㅡ 4.778, datado de 27 de dezembro de 1923. Segundo seu estatuto, uma de suas finalidades era "a realização de um programa de Higiene Mental e de Eugenética no domínio das atividades individual, escolar, profissional e social" (LBHM, 1925, p.223).

Para atingir seus objetivos, o Estatuto da MBHM declarava como uma de suas principais incumbências "atuar junto dos poderes públicos federais, estaduais e municipais, sugerindo medidas e obtendo realizações que pudessem propagar as modernas ideias de profilaxia mental" (LBHM, 1925, p.224).

É sobre a LBHM, portanto, que incidirá nossa análise, definindo como recorte temporal os anos de 1925 a 1947, datas de início e presumível encerramento das atividades da Liga e período em que ocorreram as publicações dos periódicos dessa associação, os Arquivos Brasileiros de Higiene Mental, fonte primária e principal deste estudo.

No período aqui tratado, vários são os atores políticos que se estabelecem por meio de movimentos sociais, associações de classe ou grupos ligados à área da saúde e a áreas que se preocupavam com as condições sociais de vida. As associações médicas começaram a surgir em 1929, com a criação da Sociedade de Medicina e Cirurgia do Rio de Janeiro. No período de 1920 a 1940, o número dessas associações se ampliou. Variadas instituições civis ou estatais se estabeleceram, enunciando diversas propostas de 'ordem sanitária', tais como o sanitarismo de Oswaldo Cruz, o Instituto Pasteur (inicialmente privado, posteriormente estatal), a Escola de Medicina, a Sociedade Eugênica de São Paulo (1914), a Sociedade Brasileira de Higiene (1923) e a Liga Brasileira de Higiene Mental (1923).

Essa preocupação com a higienização do país foi gerada no bojo da crescente urbanização e em função das mazelas sociais presentes no país desde então. Segundo Lima e Hochman (2000), as mazelas sociais presentes no Brasil do século XIX e ainda no início do século XX estavam relacionadas à herança colonial (de 'hábitos rudes' e 'anti-higiênicos'); à composição étnica da população (com o predomínio de raças ditas inferiores, tais como indígenas e afrodescendentes); à ausência do poder público nas áreas de saúde (falta de saneamento básico, por exemplo) e de educação (grande número de analfabetos, por exemplo).

Sabemos que a preocupação com a higiene data de tempos remotos. Entretanto, é na sociedade capitalista (potencializadora da urbanização), quando as altas taxas de morbidade e mortalidade da população ameaçam paralisar o desenvolvimento das forças materiais de produção, que a preocupação com a higiene se torna uma questão de saúde pública. O avanço científico proporcionado pelo desenvolvimento das ciências naturais, como resultado das necessidades do próprio sistema capitalista, durante o século XIX e início do século XX, forneceram um aparato técnico e teórico para o desenvolvimento de uma série de medidas de intervenção sobre o meio, com o objetivo de diminuir as influências patogênicas sobre os corpos. Nesse momento, a preocupação com a higiene passa a ser compreendida como efeito de lutas no campo médico que, pouco a pouco, faz emergir variadas instituições.

A higiene, então, passa a ser definida como "o ramo da medicina que se ocupou da descrição e redescrição dos objetos sociais em conformidade com os cânones desta Ciência; ... ramo que se preocupou, sobretudo, com uma medicina do social" (Gondra, 2000, p.521). 
De acordo com Fontenelle (1925, p.1), membro honorário da LBHM:

A rápida evolução que vai tendo a higiene pública, como forma de atividade social baseada na utilização das ciências físicas e biológicas, levou-a a alargar grandemente as suas responsabilidades, incluindo um trabalho construtor da natureza nimiamente ativa, muito além da simples passividade de defesa contra a doença.

Baseado nos novíssimos conceitos da bacteriologia e da fisiologia, o desenvolvimento das ciências físicas e biológicas, como apontou Fontenelle (1925), permitiu um importante avanço no controle das condições de vida da população, que nesse período passava por grandes transformações. Essas transformações, proporcionadas por uma expansão mundial do capital, provocaram o crescimento descontrolado dos centros urbanos, para onde se dirigiam milhares de trabalhadores vindos do campo em busca de trabalho.

Essa expansão mundial do capital não é mero fruto do acaso. Nas palavras de Basbaum (1976, p.129), "é um destino fatal do capitalismo crescer e expandir-se à custa de nações mais débeis". Nas nações em que a concentração da produção e do capital alcançou um nível tão elevado que rompe as fronteiras nacionais, a exportação de mercadorias passa a dar lugar à exportação de capitais e se transforma em imperialismo. O Brasil não saiu intacto desse processo de expansão do capital mundial. Muito pelo contrário, os interesses imperialistas das nações economicamente mais fortes contribuíram para alimentar no Brasil o anseio de modernização e seu estabelecimento como nação. Trata-se de um momento em que vultuosos empréstimos foram realizados pelo Estado brasileiro, como forma de se obter capital para ser investido na cafeicultura, pois o café brasileiro ganhara espaço no mercado externo.

Além da penetração e crescente influência do capital estrangeiro, outros acontecimentos marcaram esse período no Brasil. Fim da escravidão, migrações e imigração. O final do século XIX é, para a história da formação social brasileira, particularmente importante não só pelas transformações que ocorrem nas relações de produção, o que modifica todo um conjunto de relações sociais, mas principalmente pelas consequentes alterações nas relações de poder político. A constituição de um complexo aparelho de Estado nacional, com a proclamação da República, dava-se em meio a transformações demográficas ${ }^{1}$ e sociais. As grandes cidades surgiam como espaço de novas possibilidades de vida. Segundo Marins (1998), novos habitantes, vindos das antigas senzalas, de casebres do interior do país e dos portos estrangeiros, somavam-se aos antigos escravos, forros e brancos pobres que já inchavam as cidades imperiais, buscando sobreviver na instabilidade desse novo habitat.

Por possuir uma estrutura sanitária inadequada e apresentar condições insalubres de trabalho e de moradia, o novo espaço urbano industrial propiciava a disseminação de doenças em massa (Ferreira, 1999). Era urgente a necessidade da construção de uma nova ordem urbana. Políticas de saneamento precisavam ser desenvolvidas para minimizar a insalubridade que se espalhava no território das cidades. Segundo Finkelman (2002), os estudos históricos sobre a constituição da área da saúde no Brasil têm privilegiado o período da Primeira República (1890-1930), como um período de grandes reformas sanitárias.

A ciência identificada com a República, em prol do desenvolvimento da nação, assumiu um papel social de responsabilidade pelo progresso. As instituições ora criadas deveriam ser 
porta-vozes dessa ciência que tanto bem faria ao país, o qual estava, segundo Gustavo Riedel, então presidente da LBHM, "necessitado ainda de mais instituições que se preocupassem com a sua defesa social, para formação definitiva do tipo nacional" (1925, p.213). Os médicos não pretendiam limitar sua esfera de ação ao domínio intelectual. Era preciso penetrar também na vida da população.

A identificação da nação com a figura de um indivíduo fraco física e mentalmente colocava o país em atraso. A figura do Jeca Tatu, cujas características foram destacadas como representativas do homem brasileiro na obra Urupês (originalmente publicada em 1918), de Monteiro Lobato, precisava ser urgentemente negada. Preguiçoso, pouquíssimo higiênico e nada requintado, o Jeca denegria a imagem da nação.

\footnotetext{
Trata-se de um dever, para nós, formal e imprescindível. Exigem-no - a criança, para seu amparo e sua proteção - a raça, para seu aperfeiçoamento; a sociedade, para a sua defesa e melhor organização; as três para um remoto ideal de humanidade feliz. ... Ouso, também, em nome da "Liga Brasileira de Higiene Mental", lançar daqui um caloroso apelo a todos quantos tão interessadamente me escutarem, para que juntos trabalhemos, sem hesitações e sem desfalecimentos, nessa benemérita campanha civilizadora que há de atestar aos vindouros a clara e elevada visão do nosso patriotismo (Vianna, 1925, p.180, grifos nossos).
}

Em busca da nação saudável, as propostas de higienização dos espaços públicos e dos corpos foram adentrando os lares brasileiros. Nesse contexto urbano, industrial, moderno, à medida que as doenças físicas foram sendo minimizadas, outra preocupação, além daquela circunscrita ao domínio da biologia e da fisiologia, começou a inquietar esses intelectuais: a 'higiene mental'. Nesse sentido, outro membro da LBHM, o médico Carlos Penafiel (1925, p.11) declara:

a máquina na indústria moderna, atividades febricitantes impossíveis com o músculo humano, assim também com o músculo animal, mas que vieram requerer muito mais das qualidades cerebrais do operário do que de suas qualidade físicas -, criaram, neste meio século último, novos problemas médicos psico-físicos que estão a desafiar a higiene pública, ou mais especialmente a Higiene Mental.

A 'higiene mental' procurou trabalhar em ligação com a 'higiene geral', mas dedicandose mais particularmente a salvaguardar a saúde psíquica dos indivíduos. Segundo Fontenelle (1925, p.1), devia-se considerar a importância da atividade psíquica profundamente entrelaçada com a física, surgindo, assim, "a higiene mental como uma cogitação especial".

A expansão das ações higienistas para este novo campo de atuação - a mente desenvolveu a ideia de que, mais do que um trabalho curativo, era necessário realizar um trabalho de cunho preventivo, voltado para a vida coletiva, intervindo no comércio, na indústria, na educação, no domínio criminológico, na imigração e, entre eles, na família, pois "os conflitos passam [passaram] a ser conflitos de desajustamento de personalidade. Desajustamentos na família. Desajustamento na sociedade. Crivado de toda a sorte de solicitações, o cérebro humano tornou-se como um arco retesado, vibrando às menores influências do ambiente" (Ramos, 1941, p.18). Hasteando a nova bandeira da higiene pública, a LBHM tornou-se um importante veículo de defesa da ordem e do progresso 
nacional, e a família 'mentalmente saudável' e 'moralmente higiênica' estava incluída na estratégia de 'nacionalização'.

É importante destacar que esse movimento médico-higienista não teve caráter popular, ou seja, não foi gerado no seio da população em geral. "Tratava-se de um pequeno grupo, em termos numéricos, formado por médicos em sua maioria e, a considerar os padrões da época, com grandes eruditos dentre eles" (Boarini, Yamamoto, 2004, p.63).

Segundo Luz (1982), os agentes sociais médicos de maior destaque não se concentravam em apenas um movimento, associação ou instituição. Daí a impressão da grande movimentação médico-social no período, advinda da grande presença daquele pequeno número de agentes mobilizando e multiplicando-se em várias instituições.

Também é importante pontuar que esse movimento não foi marcado pela homogeneidade de modelos de conhecimento e de prática, pelo contrário, por vezes, eram apresentadas ideias e propostas conflitantes, tais como as ideias eugenistas e higienistas. Entretanto, por mais divergentes que pudessem ser, esses modelos médicos de conhecimento e de prática caracterizavam-se sempre por ter o Estado, constituído como aparelho, como interlocutor e propunham serem dele o discurso e a estratégia política dominantes. Todos exprimiam o propósito de constituir a ordem social e política do capitalismo, sublinhando sempre o caráter objetivo da intervenção científica na sociedade, supondo a ciência como universal e as técnicas como neutras.

Os higienistas apontavam o meio como fator decisivo para os problemas de personalidade e desajustes sociais. Já os adeptos da eugenia localizavam o fator decisivo dos males na herança genética. Para nos ajudar nessa diferenciação, citaremos o doutor Mirandolino Caldas, que, em 1932, era o diretor da Clínica de Eufrenia e secretário-geral da Liga Brasileira de Higiene Mental, também membro honorário da Liga Argentina de Higiene Mental.

De acordo com o conceito desde muito consagrado, a higiene não é uma ciência no rigor do termo; é, antes, um conjunto de dados e de conhecimentos extraído das ciências físicas e naturais e, particularmente, das ciências médicas, formando um verdadeiro código que ensina ao homem os preceitos indispensáveis á conservação da saúde. A higiene ensina a evitar as doenças e a conservar a saúde dentro de sua relatividade, defende o indivíduo e a sociedade da voragem das epidemias, mas não estuda os meios de firmar o tipo morfologicamente perfeito. Este estudo pertence à eugenia (Caldas, 1932, p.30).

Vemos, então que a eugenia se tornou uma ciência à parte, preocupada com a boa formação física e hereditária do indivíduo. Tomando do grego, os radicais 'eu' e 'genia' significa 'bom nascimento'. Diferentemente dos higienistas, que acreditavam na possibilidade de se minimizarem os problemas de desajustamento social pelas medidas de educação e sensibilização da população, os eugenistas defendiam a ideia de eliminação dos desajustamentos, principalmente por medidas que impossibilitassem a procriação dos considerados inferiores, ou seja, todos aqueles que não se enquadravam nos ideais burgueses de classe branca, sadia, disciplinada, polida e civilizada.

Eleita como representante da classe dominante, à raça branca se associou a ideia de 'superioridade'. Assim, os eugenistas se propuseram a resolver os problemas de formação racial da nação brasileira, 'contaminada' pela miscigenação racial com raças 'inferiores': 
asiáticos, negros, índios, entre outros. Propunham mais rigor em relação às leis de imigração, para que vetassem a entrada de imigrantes doentes ou fracos e realizassem a extradição daqueles que adoecessem e não mais poderiam servir à nação (Oliveira, 1932).

Propunham também a esterilização dos desajustados, doentes mentais, dos criminosos, dos deficientes físicos, ou seja, de todos os que destoassem do ideal de perfeição burguesa. Para Renato Kehl, por exemplo, um dos principais expoentes do movimento eugênico no Brasil e membro da LBHM, era um verdadeiro disparate promover medidas educativas e de sensibilização higiênicas para esses 'infra-homens', como os denominava. Tais medidas, segundo ele, feriam a lei natural de prevalência do 'mais forte':

O mal vem de muito longe e ainda não foi suficientemente evidenciado, porque não se vai à raiz da questão. A taça que vinha se enchendo, transbordou no nosso século. O mal é antigo, provém, essencialmente, da viciação das leis naturais, da civilização que permitiu a anulação de preceitos básicos que garantiam a vitória dos melhores - e impediam o acúmulo de incapazes e de nocivos à coletividade ... processado sob a capa protetora de filantropia contra-seletiva (Kehl, 1932, p.9).

De acordo com Stepan (2005), os estudos genéticos e eugênicos do período em destaque neste artigo criaram e deram significado científico e social a novos objetos de estudo, como, por exemplo, aos indivíduos ou aos grupos supostamente inadequados hereditariamente (ou 'disgênicos') que constituíam populações humanas particulares. Nesse sentido, essa autora procurou demonstrar que a ciência e o movimento social que se associou ao, então, novo campo da genética - o movimento eugênico - passaram a reivindicar autoridade para produzir técnicas que conformavam interpretações culturais e levavam ao desenvolvimento de estratégias sociais de 'limpeza racial'.

Já para os higienistas, o estudo de gêmeos criados em condições desiguais de ambiente mostraram que quanto maior era a diferença do ambiente, maiores eram as diferenças comportamentais e de personalidade. Arthur Ramos, sob a influência da psicanálise, foi um dos higienistas que contribuiu para a popularização das concepções de higiene mental nas décadas de 1930-1940, procurando sensibilizar a população quanto à necessidade de cuidados, os quais ele denominava higiene do espírito: ${ }^{2}$ De acordo com Ramos (1941, p.36), um membro da LBHM que não era adepto das ideias eugênicas, esses estudos com gêmeos corroboraram a ideia de que "as influências ambientais estão no primeiro plano como fator decisivo na formação da personalidade humana".

A partir desses estudos, os higienistas procuravam desmontar a ideia de influência decisiva da herança genética sobre a formação da personalidade. Essa influência, segundo Ramos (1941, p.35), precisava ser desmitificada, visto que era tida como um novo 'totem', como se "a sorte da humanidade estivesse entregue a essas entidades, a quem é preciso render homenagens rituais, para afastarem os 'fardos' que pesam sobre uma vida humana".

Vale ressaltar que, mesmo existindo contradições epistemológicas ou ideológicas, higienistas e eugenistas concordavam sempre com as explicações dadas para os problemas sociais. Para eles, pauperismo, condições deficitárias de saúde e higiene, subalimentação e incultura eram fenômenos que tipificavam obstáculos para o desenvolvimento da nação. Esses fenômenos não eram entendidos como uma consequência das contradições da ordem capitalista, mas como perturbadores dessa ordem. A matemática era a seguinte: meio social 
desestruturado gera indivíduos desestruturados, os quais, por sua vez, reproduzirão ainda mais desestruturação social. Para acabar com o problema, tornou-se necessário higienizar os 'desajustados', para que eles não continuassem a desestruturar a ordem.

Independentemente de as ideias se situarem mais no terreno da eugenia ou da higiene mental, o que pretendemos destacar neste artigo é que, instrumentalizando-se a partir da produção científica da época, essas duas concepções enfatizavam as diferenças de raça e de gênero e concentravam seu olhar na reprodução humana como arena para a atuação da ciência e das políticas sociais (Stepan, 2005).

Não queremos aqui reproduzir a discussão antiga bastante presente no período abordado, que colocava em oposição cultura versus biologia, no que diz respeito a suas influências sobre o desenvolvimento humano. Ao contrário, queremos, ainda que de forma breve, salientar que tanto aqueles que defendiam a primazia da cultura quanto aqueles que defendiam o primado da biologia descartavam o fato de que as diferenças entre as raças ou entre os gêneros estavam em íntima relação com o modo de organização material e social da vida humana do período.

Costa (1989) salientou a mesma associação aqui tratada. Em seu trabalho, o autor procurou demonstrar que os profissionais que atuaram na LBHM, utilizando-se de um ideal eugênico, "confundiram suas aspirações sociais e políticas com programas de prevenção e proteção à saúde mental dos brasileiros" (p.175). Neste artigo, não enfocaremos os aspectos gerais da LBHM, rigorosamente abordados por Costa (1989). Nosso foco será sobre uma das preocupações da LBHM, a saber, a família, sobre a qual os profissionais dessa associação dirigiram forte discurso e intervenção. Por isso, damos destaque às ideias higienistas. Para os higienistas, era 'incontestável' a ideia de que o meio influenciava o desenvolvimento dos indivíduos e que, principalmente, a família imprimia marcas indeléveis no destino do homem, tal como afirma Ramos (1941, p.64): "É nas constelações familiares, no romance neurótico de família, que se vão encontrar os germes dos desajustamentos humanos futuros, na vida social". Tornou-se necessário, portanto, estruturar essa família para, dessa maneira, estruturar a nação.

\section{O'ideal de família'}

A infância ganhou lugar de destaque nas intervenções e encaminhamentos propostos pela LBHM. Na antiga estrutura familiar patriarcal, o pai ocupava o lugar central. $\mathrm{Na}$ família higiênica, a infância ganha o 'ar de majestade'. Na família colonial, a criança era manipulada pela religião (educada para ser o 'anjinho' inocente) e propriedade da família, sem maiores destaques e participação na vida familiar (Costa, 1999).

Mas, na família burguesa que se firmava como célula mater da sociedade, a preocupação higiênica procurou difundir a concepção de criança saudável, fisicamente bonita e mentalmente dotada para, futuramente, tornar-se um adulto equilibrado e um reprodutor hígido. Oliveira (1929a, p.802), representante da LBHM no Terceiro Congresso Brasileiro de Higiene (1926), afirmou que "falar em educação sanitária, é lembrar que ela é irrealizável sem formação de hábitos sadios, que estes se formam na criança e se tornam tanto mais difíceis com a evolução da idade, para se tornarem quase irrealizáveis na idade adulta". 
De acordo com Ramos (1941, p.21), "o adulto é um ser formado, com seu passado de erros e incompreensões. ... Mas na criança, podemos prevenir o aparecimento desses conflitos e desses desajustamentos". Assim, a criança se tornou o grande campo de aplicação da higiene mental. "Cuidando da infância, a higiene mental quer [queria] pôr um paradeiro na onda do crime, da neurose, da loucura, dos conflitos de ajustamento de toda natureza, ou dos inúteis e desocupados que atravancam as avenidas das grandes cidades" (p.23).

Além de se preocupar com a futura formação do cidadão saudável, pleno trabalhador e construtor da nação, a higiene mental trouxe à tona problemas sérios relacionados à infância, tais como os altos índices de mortalidade, desnutrição, abandono, problemas de aprendizagem e de comportamento escolar, falhas no desenvolvimento, transmissão congênita e hereditária de doenças, falta de cuidados gerais.

Os higienistas acreditavam que boa parte dos males que assolavam a infância poderiam ser vencidos pela boa instrução dos pais e educadores no trato com as crianças. No entanto, mais uma vez a explicação naturalizada para os problemas sociais não levava em consideração o fato de que, antes de levar as mãos à torneira para serem lavadas, era preciso fazer chegar a água na torneira.

Acreditavam que o problema poderia ser resolvido, em grande parte, pela formação de hábitos sadios nas crianças, o que deveria ocorrer desde o nascimento. "Na primeira e segunda infância devemos ensinar os preceitos de higiene aos pais, nutrizes e as pessoas que com elas convivem" (Ramos, 1941, p.870). Segundo Fontenelle (1925, p.8),

Os hábitos mentais iniciam logo após o nascimento, quando devem ser formados os hábitos de regularidade para dormir e para se alimentar. Essas primeiras adaptações levarão o indivíduo a se ajustar às condições sociais, para uma convivência harmônica, o cuidado com a inteligência e com a conduta do indivíduo deverá ser realizado ainda na fase de criança.

Além dos hábitos físicos, os hábitos mentais, tais como os da alegria, de pureza, de solidariedade humana, de verdade e de autoconfiança deveriam ser incutidos desde cedo, transmitido pelos pais aos filhos, mesmo antes de eles ingressarem na escola (Sá, 1929).

Pouco a pouco está encaminhando em nosso meio a ideia de cuidar-se da saúde das crianças das escolas, de fazer-lhes a educação higiênica, de examinar-se-lhes sistematicamente o corpo e o espírito e de corrigirem-se-lhes os defeitos e desvios. Todavia, para certas questões da saúde física e para quase todas as de higiene mental, é preciso cuidar da criança antes do período de escolaridade (Fontenelle, 1925, p.7).

A redefinição da infância, colocando a criança no centro da órbita familiar, provocou mudanças na organização da 'vida conjugal'. E o discurso higienista contribuiu com esse processo de redefinição das leis de amor e sexo na vida familiar.

Isso fez com que a seleção do parceiro conjugal se tornasse uma questão capital para a higiene. A saúde do filho não dependia apenas do cuidado que a ele era dispensado após seu nascimento, mas da vida pregressa dos pais, devendo eles ser bem dotados de saúde e de hábitos exemplares. Olinto Oliveira (1929a) trata dessa questão afirmando, em um de seus textos publicados nos anais do Terceiro Congresso Brasileiro de Higiene, que se uma mãe perguntasse a um filósofo sobre a idade que deveria começar a educar seu filho, ele 
responderia a ela que há cem anos ela o deveria ter começado, pelos cuidados educativos que seus antepassados deveriam já ter transmitido a ela.

Assim, a higiene mental passou a postular normas de seleção para escolha dos cônjuges. A coesão do casal e a concretização do casamento passaram a depender das condições físicas e mentais dos pretendentes. Esses deveriam estar bem ajustados aos preceitos de higiene física e mental, inclusive moral, para que a união fosse considerada aceitável.

Para procriar um filho predisposto à moralidade, dever-se-á (preceito nô1) escolher a pessoa com que se deseja procriar entre as que ofereçam garantias morais bem averiguadas. Para isso é de primordial importância apurar tanto quanto possível qual o calor moral das ascendentes. As possibilidades são favoráveis em grau máximo quando assim se consegue estabelecer uma predisposição bilateral à moralidade. Se não for possível conjugar genitores de convicção semelhantes, é necessário que, pelo menos na aparência, reine a harmonia no casal (Lopes, 1925, p.186, grifo do original).

Nessas afirmações de Ernani Lopes, também membro da LBHM, pode-se ver a ideia de que a 'higiene moral' da família repousa, antes de tudo, sobre o exemplo dos pais. E nesse ponto se estabelecia, para os higienistas, uma diferença entre a 'higiene intelectual' e a 'higiene moral'. Lopes (1925, p.186) apontou que "pais ignorantes podem exortar os filhos a instruírem, e conseguí-lo, ao passo que um pai bêbado, ou debochado, ou glutão, debalde exaltaria a temperança, a continência, ou a sobriedade".

O papel da sexualidade na vida do casal assumiu, da mesma forma, nova função. A sexualidade antes reprimida no casamento pelas ideias religiosas, sendo o sexo apenas destinado a fins procriativos, agora, na família higiênica, passou a ser valorizada. De acordo com o professor Olinto de Oliveira, na palestra intitulada "O amor e a higiene mental",

o exercício prematuro das funções sexuais enfraquece sensivelmente a capacidade afetiva. Assim, são as próprias leis biológicas que exigem da mocidade a continência, até que se complete a sua evolução normal, de acordo com as conveniências sociais. Mas nem só esses aspectos biológicos e sociais comportam a questão do amor e da higiene mental. ... Evidentemente, o que é sempre possível aconselhar, pesados todos os prós e contras, é o casamento, prescrição que, aliás, tem o médico o direito de fazer para clientes de um e de outro sexo (Oliveira, 1929b, p.156-157).

Podemos ver que a higiene mental contribuiu para remodelar a problemática da sexualidade, antes reprimida em termos religiosos, agora reprimindo a sua prática irresponsável e precoce. O lugar adequado para o desenvolvimento sexual e consequente fortalecimento da capacidade afetiva passou a ser o casamento, desde que, é claro, antes se analisasse bem 'os prós e os contras'. Ou seja, no casamento, o amor higiênico tinha limites, ao contrário do amor romântico e apaixonado.

Além disso, o discurso sobre o amor possibilitou a conversão quase completa da figura sentimental do homem ao personagem do 'pai' e a figura sentimental da mulher ao personagem da 'mãe'. O compromisso com os filhos passou a ser a 'pedra angular' da união conjugal, determinando a identificação entre masculinidade e paternidade, e feminilidade e maternidade.

Ramos (1941, p.59) caracterizou a mãe como "grande compensador de energias psíquicas, écran, para onde a criança polariza o seu dinamismo instintivo e afetivo". Em seguida 
caracterizou a figura paterna como "um seletor de emoções. Ele contrabalança a influência materna, exercendo o papel de mediador entre mãe e filho". Termina afirmando que os pais têm extraordinária responsabilidade em relação à higiene mental.

A necessidade de indivíduos fortes, sadios, robustos e bonitos para a construção da nação redefiniu o papel social da mulher. Surgiu a figura da 'mãe extremosa', amante dos filhos. O discurso higienista em muito contribuiu para legitimar essa concepção de feminilidade. Segundo Oliveira (1929a, p.810), "instruir a mãe ou as futuras mães, é elemento primordial na formação de hábitos sadios nas crianças. Essa instrução, racionalmente se inicia no domicílio para se continuar pelas escolas e organizações de assistência e instrução sanitárias".

Foi por intermédio das mães que a higiene mental procurou agir na formação dos hábitos da criança (Ramos, 1941). Essa mulher, consciente de sua maternidade, deveria ser dotada instintivamente de um sentimento em que o 'mito do amor materno' encontrou forte sustentação nas 'necessidades' impostas pela sociedade e se popularizou, entrando pelos lares e trazendo consigo o fardo de, se preciso, 'padecer no paraíso', mas, acima de tudo, ser mãe!

Os membros da LBHM acreditavam que instruir pela demonstração concreta, pela assistência sanitária, conjuntamente as mães e seus filhos, era, sem dúvida, o caminho a ser seguido.

Panfletagem, clínicas de orientação, escolas maternas e jardins de infância se difundiram nesse período, pela intervenção desses intelectuais no serviço público e particular, com essa nobre finalidade: auxiliar as mães em sua sublime missão.

Desde a amamentação até a inserção da criança na escola, a tarefa da mãe foi sendo modelada pelo especialismo. A 'verdade' das mais novas descobertas ou dos mais recentes estudos sobre a relação mãe/filho precisava libertar as mães de seus erros e compreensões equivocadas, na execução de sua grandiosa obra educadora:

É aí que intervém o fator capital da vida da criança, a mãe, cuja influência do ponto de vista especial que nos ocupa, o da educação do recém-nascido e do lactante, não me parece ter sido ainda devidamente compreendido e utilizado ... Para isso, entre outras noções precisa ela conhecer como se faz o desenvolvimento psicológico da criança e sobre os princípios de higiene que lhe são aplicáveis, principalmente os que se referem à alimentação (Oliveira, 1929a, p.851).

O homem, da mesma maneira que a criança e a mulher, também teve o seu papel social amplamente redefinido pela nova organização da vida material. Ele deixara de ser o centro da órbita familiar, o patrão-proprietário dos destinos pessoais e de todos os bens materiais que os cercavam.

Como citado, o pai 'higiênico', segundo Ramos (1941, p.59), era um "seletor de emoções, responsável por contrabalançar a influência materna e mediar a relação mãe-filho, exercendo sua função de censura".

Em novos moldes, seu papel social de provedor material e autoridade do lar, chefe de família, fora mantido. Contudo, nesse novo contexto, sua principal propriedade era sua força de trabalho, e sua autoridade deveria ser exercida com muito afeto. Não deveria ser o pai que castiga, mas aquele que corrige de maneira dosada e sábia (Ramos, 1941). 
A sexualidade masculina deveria ser contida até o casamento. Estudos endocrinológicos apontavam incontinência sexual antes do casamento como causadora de prejuízos em relação à virilidade masculina. A fornicação deveria ser evitada, dado o número assombroso de doenças sexualmente transmissíveis que proliferavam no país. A ilegitimidade dos filhos e a prática sexual irresponsável deveria ser contida, principalmente pelo problema da orfandade que superlotava as casas de abrigo infantil, provocando altos índices de mortalidade.

Os membros da LBHM também se preocuparam em difundir os ideais de higiene mental para os homens, porém, de forma bem menos representativa em relação ao preconizado para as mulheres. Alguns representantes da LBHM realizaram palestras em quartéis militares sobre doenças sexualmente transmissíveis, outros fizeram estudos sobre os fatores endócrinos na incontinência masculina, sempre defendendo a ideia de que o casamento era a relação segura para o desenvolvimento pleno da sexualidade masculina: "A continência masculina até o matrimônio, mesmo quando apreciada exclusivamente sob o ponto de vista endocrínico, deve ser praticada, porque dá em resultado maior desenvolvimento da glândula intersticial e, daí, maior atividade e vigor corporais e psíquicos" (Fonseca, 1939, p.11).

Dessa forma a higiene mental contribuiu para a legitimação dessa constelação familiar burguesa, nuclear e conjugal.

Alguns dispositivos de orientação e apoio foram fundamentais nessa higienização mental da família. "Difundiram-se as clínicas de higiene mental preventiva, para orientação da primeira infância e da infância escolar, bem como as Clínicas Ortofrênicas de correção para essas 'crianças problemas' do lar e da escola" (Ramos, 1941, p.22).

\section{Saúde da família sinônimo de saúde da nação?}

Pela mão dos higienistas, membros da LBHM, a questão da saúde da família e sua forma de organização moral, intelectual e sexual foi introduzida na pauta de discussões, estudos e intervenções dos preceitos de higiene pública da época.

As relações intrafamiliares deveriam expressar a construção de uma nação 'ideal', ou seja, uma nação saudável, pautada nos moldes da classe que se apropriava do poder - a aristocracia rural e a burguesia branca -, e deveriam adquirir um estilo refinado, higiênico, polido e disciplinado. Esse era o indivíduo 'ideal' para construção da nação brasileira, o qual poderia elevá-la ao nível de civilização nos parâmetros europeus. Esse corpo saudável e essa mente higiênica, eleitos representantes de uma classe e de uma raça, serviram para construção de uma ideia de 'superioridade racial e social'. Sendo assim, a intervenção da LBHM sobre a família traz em si as marcas de um processo de 'depuração social' que consiste em separar indivíduos superiores de inferiores, normais de anormais, degenerados e menos evoluídos dos mais evoluídos. Essas ideias passaram a propor regras até mesmo para as escolhas conjugais e para a organização da vida sexual nas famílias.

Vale lembrar que o desenvolvimento urbano e a criação do Estado nacional reclamavam novos hábitos familiares. A família numerosa, constituída de muitos filhos, legítimos ou não, marcada pela silenciosa submissão e dependência da mulher, cercada de inúmeros empregados, escravos e agregados, não fazia mais sentido. 
A urbanização aos poucos foi impondo a diminuição do tamanho das casas e mudanças na sua arquitetura. ${ }^{3}$ A mão de obra livre foi impondo a diminuição dos empregados e agregados, e logo a família procuraria se resguardar, cercada pelos sentimentos de privacidade e intimidade. O tamanho da família passaria a se restringir a pai, mãe e filhos, estes últimos em número bem mais reduzido.

Nesse cenário de transformações, os princípios da higiene sanitária foram transportados à higiene mental, recorrendo-se às ciências naturais para compreensão e intervenção no campo das relações sociais.

Por um lado, os higienistas apontavam para a superação de problemas emergentes que necessitavam de intervenção, como a necessidade de combate às doenças epidêmicas, aos focos de epidemia, de vacinação da população, de saneamento, esgoto, água potável, alimentação adequada, higiene, vestuário, condições salubres de moradia e de trabalho, educação, combate ao alcoolismo, à violência etc. Em muito, esses profissionais contribuíram com orientações valiosas para a superação dessas necessidades. Por outro lado, ao transportar as explicações e soluções advindas das ciências naturais para os problemas sociais, os higienistas alienavam desses fenômenos as contradições geradoras e mantenedosras das desigualdades sociais. A isso chamamos de naturalização do social, ou seja, uma alienação do movimento histórico-econômico que rege a sociedade em determinado momento, na qual, no limite do 'ser natural', o ponto de partida e de chegada para a 'ordem e progresso', é sempre o indivíduo em particular e/ou a soma deles.

Assim, os higienistas associavam os 'males da Nação', tal como as 'raças inferiores', os 'deliquentes', os 'preguiçosos', aos problemas/desajustes mentais ou morais dos indivíduos particulares. Isso implicava, ao mesmo tempo, o estudo e uma ação no plano subjetivo do ser humano. Tornou-se necessário desenvolver uma intervenção que pudesse modificar a forma de pensar, os hábitos e os costumes da população. Essa premissa guarda identidade de pensamento com o positivismo, que afirma:

na medida em que o curso natural dos acontecimentos caracteriza a grande crise moderna, a reorganização política se apresenta cada vez mais como necessariamente impossível sem a reconstrução prévia das opiniões e constitui, pois, nossa primeira necessidade social, igualmente quanto à ordem e progresso (Comte, 1988, p.43).

Nessa identificação, o que escapou às lentes daqueles intelectuais no início do século $\mathrm{XX}$ foi o fato de que a sociedade que necessitava de indivíduos 'bem adaptados e sadios' era a mesma que gerava as 'dificuldades de adaptação' de outros indivíduos, pela produção de condições sociais desiguais, que geravam situações de vida desiguais. Por tratar-se, de uma construção coletiva, com problemas e necessidades diversos, as orientações higienistas muito contribuíram em alguns aspectos, como no saneamento, no tratamento de toxicômanos (alcoolismo, principalmente), na prevenção de doenças transmissíveis e hereditárias, no cuidado prestado ao doente mental, entre outros.

Mas o não entendimento das desigualdades e contradições sociais do ponto de vista histórico levou os higienistas a localizar as diferenças de 'ajustamento social' nos próprios indivíduos. Aqueles que não se 'ajustassem' ao meio seriam considerados inaptos, por serem destituídos dessa 'verdadeira essência', natural, adequada e condizente com a sociedade capitalista. 
Assim, podemos entender como as preocupações com a saúde da família, desde o seu aspecto físico até o seu aspecto mental, se tornaram alvos das políticas públicas nas primeiras décadas do século XX no Brasil, a fim de, transformando hábitos e atitudes das populações urbanas, adaptá-las às necessidades da ordem burguesa em construção. Esse era, para a LBHM, "um dever formal e imprescindível na benemérita campanha civilizadora que atestava a sua elevada visão de patriotismo", retomando as palavras de Vianna (1925, p.11).

Reafirmando Morgan (1877, citado por Engels, 2006. p.41), a família é uma instituição que, enquanto parte da organização social dos homens, vai-se transformando à medida que essa mesma organização social se altera. Portanto, a família necessária para esse momento histórico era a família saudável, pois da 'saúde da família' se constituiria a 'saúde da nação'.

\section{Considerações finais}

A necessidade de uma família reduzida para aquele período não significa que, como num passe de mágica, todos aqueles 'personagens' (empregados, agregados e escravos) que outrora cercavam a família oitocentista de elite simplesmente deixaram de existir. Não se trata de um conto de fadas no qual tudo o que provoca desarmonia na trama se dissolve pelo simples movimento da varinha de condão. Na história real dos homens, nem mesmo as mais belas palavras recitadas diante das adversidades têm o milagroso poder de remover pedras, como o "abre-te sésamo". Com palavras e ideias os higienistas tentaram remover as 'pedras' que escondiam os tesouros do conhecimento e da ciência, procurando sensibilizar a população em geral quanto às necessidades básicas de higienização dos hábitos físicos e 'mentais' para dissolver toda e qualquer 'desarmonia social'.

A miséria, a fome, o crime, a delinquência, o alcoolismo, a doença mental, os problemas escolares, os desajustamentos familiares, entre outros, foram em geral classificados como problemas de adaptação física ou mental dos indivíduos, ou das famílias, ao meio, tal como podemos observar no excerto a seguir:

A miséria e a fome derivam, exatamente, de outras causas. Há, sem dúvida, excesso de gente no planeta, mas de gente de baixa categoria física, psíquica e intelectual, que come e não produz, que sem trabalhar, agita-se nocivamente, perturbando o equilíbrio social (Kehl, 1932, p.6).

Podemos observar nessas citações que, embora as condições do meio possam até ser reconhecidas como empecilhos para a 'adaptação' do indivíduo, ainda assim, ele é responsabilizado pelo seu 'desajuste': o pobre é responsável por existir, por não produzir, por não trabalhar, o toxicômano é responsável por seu vício; a criança mimada e seus pais são responsáveis pelos seus problemas de comportamento.

Dessa forma, perdendo-se de vista as contradições sociais, tentava-se transferir o ideal do homem burguês europeu para um país de situação eminentemente rural, com população negra ou mestiça, herdeira de uma forte influência colonial e escravista, na qual se instalava um grande número de imigrantes que traziam na bagagem seus costumes e hábitos culturais. 
Era o mesmo que trazer a Torre Eiffel para dentro da favela carioca, como bem ilustrara Tarsila do Amaral em 1924, na tela intitulada 'Carnaval em Madureira'.

Ao refletir sobre os determinantes sócio-históricos que condicionaram o encontro e/ou desencontro dos programas de higiene pública, em especial de higiene mental, com a família brasileira de 1920-1940, favorecidos pelo distanciamento temporal, podemos perceber que, embora determinadas a solucionar as mazelas sociais do período, as propostas dos higienistas evidenciam um contraste entre a 'família ideal' (proposta por eles) e a 'família real' de que nos falam a história e a literatura da época.

Oito décadas depois que a LBHM foi reconhecida como órgão de utilidade pública e passou a apresentar encaminhamentos e propostas de intervenção à saúde da família brasileira, podemos reconhecer atualmente nas propostas de intervenção sobre a saúde mental da família brasileira, mais especificamente no Programa Saúde da Família, alguns encaminhamentos que parecem guardar alguma semelhança com aqueles propostos pelos higienistas: instruir a população em relação aos cuidados gerais de saúde; procurar zelar pela saúde coletiva; procurar desenvolver cuidados voltados para a puericultura, o controle das doenças transmissíveis e hereditárias; desenvolver atendimento domiciliar por meio de profissionais visitadores; propor o cuidado físico e mental no seio familiar, pelo serviço de uma equipe multidisciplinar, composta por vários profissionais, entre eles, os psicólogos integrados às equipes de Saúde da Família, por meio dos Núcleos de Apoio à Saúde da Família.

No entanto, nesses encaminhamentos, que localizam a família como base estratégica de transformação social, mais uma vez as contradições sociais não são consideradas.

Os tempos, a situação contextual, as famílias e os profissionais são outros. No entanto, apesar das transformações ocorridas, quer na família, quer nos profissionais que intervêm sobre ela, a busca de solução para as mazelas sociais parece continuar sendo atribuída ao indivíduo em particular, e a família vista como expressão desse indivíduo que vai ser chamado para assumir responsabilidades sociais na direção não só do 'progresso', mas também da 'ordem' social.

Refletir sobre determinantes sócio-históricos que condicionam a construção de políticas de saúde mental voltadas para o contexto familiar atual pode ajudar-nos a construir práticas e intervenções que rompam com a visão naturalizada de família, ainda hegemônica no campo da psicologia. Essa visão naturalizada de família - fundamentada na ideia de que essa instituição possui dinâmica própria, que independe do movimento do conjunto das relações humanas e do surgimento de novas necessidades, não sendo vista como um produto do modo de produção na vida dos homens - acaba por legitimar a construção de práticas tutelares sobre o contexto familiar. Ou seja, práticas que venham declarar a 'verdade' sobre a forma de se estabelecerem vínculos familiares, ou de se viver em família, determinando 'modelos ideais' que, quando não alcançados, produzem toda ordem de sujeitos 'desviantes' e 'desajustados' à norma social estabelecida.

Compreensões naturalizadas das relações sociais apenas obscurecem as contradições sociais existentes no modo de produção vigente, fazendo-nos perder de vista que a mesma sociedade que produz a 'família ideal' produz a 'família desajustada'; a mesma sociedade que produz a riqueza, produz a pobreza. Pensar nessas questões talvez possa nos auxiliar a romper com a legitimação de psicopatologizações e medicalizações desnecessárias. 


\section{NOTAS}

${ }^{1}$ Numericamente, a população cresceu de forma significativa no período histórico aqui tratado. "Ao ser instituído o regime republicano o recenseamento (1890) assinalava uma população de 14.333 .915 habitantes. Trinta anos depois, em 1920, éramos 30.635.605, em 1925, 35.804.704 e em 1940 (recenseamento) 40.272.650. Entre 1890 e 1920, a população crescera quase duas vezes e meia" (Basbaum, 1976, p.140).

${ }^{2}$ Este artigo voltou-se para o estudo das propostas e intervenções de higiene mental para a família brasileira do início do século XX. Em função disso, o olhar e a atenção aos textos produzidos pelos higienistas do período em questão voltaram-se para aqueles em que os ideais de higiene mental fossem mais expressivos, No entanto, podemos citar outros textos em que é possível verificar as propostas eugênicas para a família ou para os membros dessa família brasileira do início do século XX, tais como Reis (2000) e Mai (1999).

3 "Nas plantas das casas grandes e de algumas residências urbanas apresentadas por Carlos Lemos, contam-se, por vezes, 5, 7, 8, 9 e até 12 quartos" (Costa, 1999, p.84).

\section{REFERÊNCIAS}

ACOSTA, Ana Rojas; VITALE, Maria Amélia Faller (Org.).

Família: laços, redes e políticas públicas. São Paulo: IEE/PUCSP. 2005

AMARAL, Tarsila do.

Carnaval em Madureira. Pintura, óleo sobre tela, 76 X $63 \mathrm{~cm}$. Tarsila do Amaral (site oficial). Galeria. Disponível em: http://

www.tarsiladoamaral.com.br. Acesso em: 25 nov. 2008. 1924.

BASBAUM, Leôncio.

História sincera da República. São Paulo: AlfaOmega. 1976.

BOARINI, Maria Lucia; YAMAMOTO,

Oswaldo $\mathrm{H}$.

Higienismo e eugenia: discursos que não envelhecem. Psicologia em Revista, São Paulo, v.13, n.1, p.59-72. 2004

BRASIL.

Ministério da Saúde. Departamento de Atenção Básica. Guia prático do Programa Saúde da Família. Brasília. 2001.

BRASIL.

Ministério da Saúde. Portaria GM no 154, de 24 de janeiro de 2008. Cria os Núcleos de Apoio à Saúde da Família, Nasf. Brasília: Câmara dos Deputados/Coordenação de publicações. 2008.

CALDAS, Mirandolino.

Editorial. Archivos Brasileiros de Hygiene Mental, Rio de Janeiro, ano 2, n.1, p.29-40. 1932.

CARVALHO, Maria do Carmo Brant.

A priorização da família na agenda da política social. In: Carvalho, Maria do Carmo Brant (Org.). A família contemporânea em debate. São Paulo: Cortez. p.15-22. 1995.

COMTE, Auguste.

Discurso preliminar sobre o conjunto do positivismo. In: Comte, Auguste. Curso de filosofia positiva; Discurso sobre o espírito positivo; Discurso preliminar sobre o conjunto do positivismo; Catecismo positivista. Seleção de textos, José Arthur Gianotti. Trad., José Arthur Giannotti, Miguel Lemos. São Paulo: Nova Cultural. p.41-61. (Os Pensadores) 1988.

COSTA, Jurandir Freire.

Ordem médica e norma familiar. Rio de Janeiro: Graal. 1999.

COSTA, Jurandir Freire.

História da psiquiatria no Brasil: um corte ideológico. Rio de Janeiro: Xenon. 1989.

ENGELS, Friedrich.

A origem da família, da propriedade privada e do Estado. Trad., Ciro Mioranza. São Paulo: Escala. 2006.

ENGELS, Friedrich.

Do socialismo utópico ao socialismo científico. Disponível em: http://www.culturabrasil.pro.br/ zip/utopicoacientifico.pdf. Acesso em: 6 jun. 2010. 1877.

FERREIRA, Luiz Otávio.

Os periódicos médicos e a invenção de uma agenda sanitária para o Brasil (1827-1843). História, Ciências, Saúde - Manguinhos, Rio de Janeiro, v.6, n.2, p.331-551. 1999.

FINKELMAN, Jacobo.

Caminhos da saúde pública no Brasil. Rio de Janeiro: Editora Fiocruz. 2002.

FONSECA, Joaquim Moreira da.

O fator endocrínico e a continência masculina até o matrimônio. Archivos Brasileiros de Hygiene Mental, Rio de Janeiro, ano 12, n.1-2, p.9-19. 1939.

FONTENELLE, José Paranhos.

Hygiene mental e educação. Archivos Brasileiros de Hygiene Mental, Rio de Janeiro, ano 1, n.1, p.1-10. 1925. 
FUKUI, Lia; BRUSCHINI, Maria Cristina Aranha. A família em questão. Cadernos de Pesquisa, São Paulo. 1981.

GONDRA, José Gonçalves.

Medicina, higiene e educação escolar. In: Faria Filho, Luciano Mendes de (Org.). 500 anos de educação no Brasil. Belo Horizonte: Autêntica. p.519-550. 2000.

KEHL, Renato.

Considerações em torno da plethora humana. Archivos Brasileiros de Hygiene Mental, Rio de Janeiro, ano 1, n.1, p.5-10. 1932.

LBHM.

Liga Brasileira de Hygiene Mental. Archivos Brasileiros de Hygiene Mental, Rio de Janeiro, ano 1, n.1, p.1-185. 1925.

LIMA, Nísia Trindade; HOCHMAN, Gilberto. Pouca saúde, muita saúva, os males do Brasil são... Discurso médico-sanitário e interpretação do país. Ciência e Saúde Coletiva, Rio de Janeiro, v.5, n.2, p.313-332. 2000.

LOBATO, Monteiro.

Urupês. São Paulo: Brasiliense. 1.ed., 1918. 2004.

LOPES, Ernani.

Resenhas e analyses. Archivos Brasileiros de Hygiene Mental, Rio de Janeiro, ano 1, n.1, p.91-105. 1925.

LUZ, Madel Therezinha.

Medicina e ordem política brasileira: políticas e instituições de saúde (1850-1930). Rio de Janeiro: Graal. 1982.

MAI, Lílian Denise.

Boletim de eugenia (1929-1931): um estudo sobre forças educativas no Brasil. Dissertação (Mestrado) - Faculdade de Educação,

Universidade Estadual de Maringá, Maringá. 1999.

MARINS, Paulo César Garcez.

Habitação e vizinhança: limites da privacidade no surgimento das metrópoles brasileiras. In: Sevcenko, Nicolau (Org.). História da vida privada no Brasil. São Paulo: Companhia das Letras. p.131-214. 1998.

MIOTO, Regina Célia Tamaso.

Novas propostas e velhos princípios: a assistência às famílias no contexto de programas de orientação e apoio sociofamiliar. In: Sales, Mione A.; Matos, Maurílho C.; Leal, Maria C. (Org.). Política social, família e juventude: uma questão de direitos. São Paulo: Cortez. p.43-59. 2004.

OLIVEIRA, Olinto.

Formação de hábitos sadios nas creanças. In: Terceiro Congresso Brasileiro de Hygiene, São Paulo, 1926. Anais... s.l.: s.n. p.801-810; 849859. 1929a.
OLIVEIRA, Olinto.

$\mathrm{O}$ amor e a hygiene mental. Actas e Trabalhos da Liga Brasileira de Hygiene Mental. Archivos Brasileiros de Hygiene Mental, Rio de Janeiro, ano 2, n.1, p.155-162. 1929b.

OLIVEIRA, Xavier.

Da profilaxia mental dos imigrantes. Archivos Brasileiros de Hygiene Mental, Rio de Janeiro, ano 5, n.1, p.16-38. 1932.

OPAS.

Organização Pan-americana da Saúde. Carta de Ottawa. Disponível em:http://www.opas. org.br/promocao/uploadArq/Ottawa.pdf. Acesso em: 8 mar. 2010. 1986.

OPAS.

Organização Pan-americana da Saúde. Declaração de Alma-Ata. Disponível em: http:// www.opas.org.br/coletiva/uploadArq/AlmaAta.pdf. Acesso em: 12 jul. 2008. 1978.

PENAFIEL, Carlos.

O elemento psychico no trabalho humano. Archivos Brasileiros de Hygiene Mental, Rio de Janeiro, ano 1, n.2, p.11-24. 1925.

RAMOS, Arthur.

Saúde do espírito: higiene mental. Rio de Janeiro: Serviço Nacional de Educação Sanitária. 1941.

REIS, José Roberto Franco.

De pequenino é que se torce o pepino: a infância nos programas eugênicos da Liga Brasileira de Higiene Mental. História Ciências Saúde - Manguinhos, Rio de Janeiro, v.7, n.1, p.135-157. 2000.

RIEDEL, Gustavo.

Actas de Trabalhos da Liga Brasileira de Hygiene Mental. Archivos Brasileiros de Hygiene Mental, Rio de Janeiro, ano 1, n.1, p.167-191. 1925.

SÁ, Carlos.

Formação de hábitos sadios nas creanças. In: Congresso Brasileiro de Hygiene, 3., São Paulo, 1926. Anais... s.l.: s.n. p.811-817. 1929.

STEPAN, Nancy Leys.

A hora da eugenia: raça, gênero e nação na América Latina. Rio de Janeiro: Fiocruz. 2005.

TERUYA, Marisa Tayra.

A família na historiografia brasileira. Bases e perspectivas teóricas. In: Encontro Nacional de Estudos Populacionais, 12., Caxambú, 23-27 out. 2000. Anais... s.l.: s.n. Disponível em: http:/ /www.abep.nepo.unicamp.br/docs/anais/pdf/ 2000/Todos A\%20Fam\%C3\%ADlia\%20na\%20 Historiografia\%20Brasileira....pdf. Acesso em: 1 maio 2010. 23-27 out. 2000.

VIANNA, Raimundo.

Os rumos da medicina social. Archivos Brasileiros de Hygiene Mental, Rio de Janeiro, ano 1, n.2, p.175-185. 1925. 